\title{
DECONSTRUIR LA CRISTIANDAD. \\ A VUELTAS CON KIERKEGAARD
}

\author{
Francesc Torralba \\ Universitat Ramon Llull, Barcelona, España
}

\section{Resumen}

Una de las ideas que recorre con fuerza toda la obra de Kierkegaard es la voluntad de comprender la esencia del cristianismo, lo que significa ser cristiano en el mundo. Esto exige, necesariamente, una crítica de la cristiandad, a la ilusión de ser cristiano, en un mundo que cree ser cristiano pero que, en realidad, ha dejado de serlo. La tarea de hacer frente a esa ilusión supone la incomprensión, una forma de sacrificio total y absoluto. Por otra parte, ser cristiano consiste en no estar jamás satisfecho con el modo de habitar el mundo, de obrar, de actuar; es nunca sentirse del todo cristiano.

Palabras clave: Cristiandad, cristianismo, sacrificio, lector, contemporáneo de Cristo.

\section{Abstract}

One of the ideas found through Kierkegaard's entire authorship is the will to understand the essence of Christianity, what it means to be a Christian in the world. This necessarily requires a critique of Christendom, a critique to the illusion of being a Christian, in a world that sees itself Christian but that, in reality, has ceased to be so. The task of dealing with this illusion implies being misunderstood, a form of total and absolute sacrifice. On the other hand, being a Christian consists in never being satisfied with the way of inhabiting the world; it is never feeling entirely Christian.

Key words: Christendom, Christianity, sacrifice, reader, contemporary of Christ. 


\section{Leer a Kierkegaard}

No elijo a un autor porque me resulte fácil leerlo. La facilidad atrofia la inteligencia, mientras que la dificultad exige trabajo intelectual y persistencia. Tampoco elijo a un autor porque sea previsible. Un autor es previsible cuando uno anticipa el final de la obra, sabe cómo va a terminar sólo con leer el prólogo. No aguarda secretos, novedades, ni giros inesperados que sitúan al lector al borde del precipicio.

Søren Kierkegaard (1813-1855) no pertenece a esta categoría de escritores. Es un autor arduo, árido; en ocasiones, tan críptico que resulta imposible entrever sus intenciones, pero, otras veces, resulta tan nítidamente claro que no es necesario ningún ejercicio especulativo, porque el texto habla por sí mismo.

Tampoco elijo un autor porque coincida con mi cosmovisión. Experimento un gran interés por los autores que me ponen entre las cuerdas, los que me hacen pensar y sufrir, que ponen en tela de juicio lo que para mí es claro y diáfano. Friedrich Nietzsche (1844-1900) pertenece a esta galaxia de escritores, pero también Arthur Schopenhauer (1788-1860), Ludwig Feuerbach (1804-1872), Sigmund Freud (1856-1939), Karl Marx (1818-1883), Jean-Paul Sartre (1905-1981) o Albert Camus (1913-1960).

Esos autores activan, en mi ser, la vida intelectual, estimulan el músculo del razonamiento, avivan el desasosiego y, a vueltas, la angustia. Le impelen a uno a examinar, a fondo, sus convicciones morales y religiosas, a indagar la consistencia racional de su cosmovisión, a plantearse, en primera persona del singular, si todo aquel edificio conceptual que le ampara y que le protege de la intemperie es un castillo de piedra sustentado por sólidos fundamentos o una chabola de caña y barro.

Considero a Søren Kierkegaard un confidente secreto, un despertador de la conciencia y un maestro espiritual, pero, también, una fuente de consolación. No es fácil bucear por sus aguas y, menos aún, en su lengua original, pero su lectura nunca me ha decepcionado. Al contrario, con el tiempo, crece mi interés por su obra a medida que la releo una y otra vez.

No me siento bien ubicado dentro de su cosmovisión, de claro cuño nórdico y luterano, a pesar de compartir profundas ideas y creencias con él, pero no es eso lo que me aproxima a su obra, lo que me impulsa a meditarlo. Es su capacidad para sacudir mi consciencia, para romper mi indiferencia como lector, para propiciar, en mí, un camino introspectivo de insospechables consecuencias. Lo considero, simultáneamente, un acicate y 
un bálsamo, una fuente de sufrimiento intelectual, pero, también, de sosiego y de pacificación interior.

A veces, sólo leo una frase, pero, con ella ya tengo bastante para meditar una hora. En otras ocasiones, presto atención a una metáfora y pongo mi mente en blanco para dejarme invadir por la fuerza de lo leído. Me doy cuenta que, a veces, lo que he leído no es absorbido, porque los pensamientos que hierben en mi interioridad son tan ruidosos y puntiagudos que se tornan refractarios a cualquier novedad, a cualquier huésped que desee ser acogido. Lo excluyen y no le dan cabida.

La lectura puede ser epidérmica, pero también puede penetrar por los poros de la piel y dejar mella en el alma. Cuando uno está profundamente saturado con su propia actividad mental o se halla inmerso en una batalla sin cuartel contra sus propios sentimientos y creencias, el texto se queda en las puertas de la casa, porque el lector lo escupe fuera de sí. Cuando, en cambio, la casa se vacía y uno cede espacio y tiempo interior, el texto se convierte en huésped y, en tanto que huésped, altera la vida y el pensamiento del anfitrión. Leer, en sentido estricto, es un acto de hospitalidad y, como tal, es hiriente.

Durante años, Søren Kierkegaard ha ocupado un lugar preeminente en mis lecturas nocturnas. Ahí estaba, en la mesita de noche, entre la lámpara y el despertador. Leía, al azar, un párrafo; después cerraba los ojos y me abandonaba a la noche sin ninguna otra pretensión que divagar hasta dormirme.

El cansancio del día actuaba como catalizador, pues cuando uno está fatigado de pelear con sus propios pensamientos, de lidiar con todo tipo de dilemas y de antinomias, experimenta lo liberador que es descentrarse de uno mismo, olvidarse de ese batiburrillo de voces que permanentemente le acompañan para hospedar al huésped y recibirlo con plena atención.

$\mathrm{Me}$ he dormido, muchas veces, paladeando una frase de Søren Kierkegaard, repitiéndola mentalmente, como si se tratara de un mantra. La lectura, cuando realmente es lectura y no un mero desplazamiento visual por el texto, constituye un acto de descentramiento, de olvido de sí y de apertura a la alteridad. Entonces se produce un choque.

Esa alteridad violenta la conciencia del lector, pero, en la medida en que se convierte, en una lectura cotidiana, se transforma, progresivamente, en un cómplice. Sin embargo, esta metamorfosis de la extrañez a la complicidad jamás se consuma en el caso de Søren Kierkegaard. 
El filósofo danés se ha convertido, con el tiempo, en un cómplice para mí o, mejor dicho, en unos de mis maestros espirituales de referencia. Y precisamente lo es porque esta complicidad siempre alberga un nudo opaco, un coágulo que se resiste a la comprensión, que activa, permanentemente, en mi ser, el deseo de conocer más y de entender, más a fondo, lo que propone. Su lectura suscita, constantemente, una invitación a conocerme más hondamente a mí mismo.

Esta recepción es disruptiva, pues altera la lógica endogámica de los propios pensamientos, el espiral autorreferencial que da vueltas sobre sí mismo, recorriendo los mismos tópicos y las mismas voces. La verdadera lectura es ruptura y, por ello, de algún modo, violencia. El otro entra en casa y altera su lógica, sus rutinas, sus tiempos y liturgias cotidianas.

\section{La ilusión de la cristiandad}

Una de las ideas fuerza que recorre toda la obra de Søren Kierkegaard, tanto los escritos de naturaleza pseudónima como los de comunicación directa, es la voluntad de comprender la esencia del cristianismo, lo que significa ser cristiano en el mundo, lo que exige el seguimiento radical de Jesucristo. Esto exige, necesariamente, una crítica de la cristiandad (Christenhed), tal y como articula en Punto de vista sobre mi actividad como escritor (Synspunktet for min Forfatter-Virksombed) (1859), pues para el filósofo danés, la cristiandad es una prodigiosa ilusión (At»Christenheden « er et ubyre Sandsebedrag).

Para el filósofo danés, la cuestión central, lo que da sentido y razón de ser a su producción escrita radica en tratar de entender lo que realmente significa ser cristiano en el mundo, en un mundo que, a su juicio, es aparentemente cristiano, o mejor dicho, se cree serlo, que se presenta, oficialmente como tal, pero que, sin embargo, ha dejado de serlo.

A su juicio, todo el mundo se llama a sí mismo cristiano sin tener conciencia de serlo. Ser cristiano se ha convertido en algo extrínseco, en un puro formalismo social.

Para conseguir tal fin, el escritor danés articula una crítica del cristianismo vivido y expresado en la sociedad de su tiempo, en las instituciones religiosas, especialmente en la iglesia luterana oficial danesa y a sus más altos representantes. Muestra cómo dicho cristianismo representa una imagen deformada y grotesca de lo que conlleva el seguimiento radical 
de Cristo, de lo que exige vivir conforme a las enseñanzas de Jesús y asumir la fe en un Dios crucificado.

La cristiandad -escribe el pensador danés- no existe. El cristianismo está esperando un escritor cómico como Cervantes, que hará del verdadero cristiano una imagen de Don Quijote. Con la única diferencia de que no será ninguna exageración literaria, como en el caso de Don Quijote. Bastará con que el escritor presente una verdadera vida cristiana, sin necesidad de recurrir a Cristo o a un apóstol. El elemento cómico se producirá, porque la época ha cambiado tanto que aparecerá como una figura cómica (...) Que un hombre, hoy día, con toda seriedad renuncie a la vida literalmente; que renuncie al amor humano, que se le ofrecía; que soporte toda clase de privaciones, pudiendo evitarlas; que de este modo se exponga a toda la angustia de la prueba espiritual... Y después se someta a ser maltratado por ello, odiado, perseguido, burlado (inevitable consecuencia de un verdadero cristianismo en este mundo): una vida como ésta, a todos en nuestra época parecerá cómica. Es la vida de un Don Quijote'1.

Søren Kierkegaard se propone, a través de su obra, abordar las consecuencias últimas que derivan de la condición de cristiano, identificar la transformación que suscita en el alma humana el proceso de conversión a la fe. A su juicio, ser cristiano no es una nota accidental en el ser de la persona; no es un dato periférico, algo así como un rasgo anecdótico, adventicio, pegado al ser de la persona como un liquen a una roca.

No se trata de un rol, ni de una función, menos aún de la ejecución de rituales o del mero cumplimiento de un código normativo. Es, más bien, una forma de existencia, un modo de articular la presencia humana en el mundo, un estadio vital. Representa, en este sentido, la adquisición de una condición, de un nuevo modo de ser, de percibir la realidad, de estar en el mundo, de concebirse a sí mismo y de concebir a los otros.

Uno no nace cristiano; uno deviene cristiano por un acto libre. Devenir cristiano constituye, a su juicio, un evento que transforma enteramente a la persona. Se trata de un acontecimiento que suscita una apertura de su ser a una realidad enteramente distinta, que produce una metanoia que opera una ruptura en la identidad personal. Uno deja de ser lo que es, para llegar a ser alguien que todavía no es; se sumerge en un espacio de incertidumbre y de paradoja, en una zona desconocida, fuera del control racional que suscita temor y temblor. Este dejar de ser para ser lo que todavía no se es conlleva, necesariamente, una profunda mutación de la identidad. Escribe el filósofo

$$
{ }^{1} \text { Pap., X } 2 \text { A } 32 .
$$


danés: "Llegar a ser cristiano se ha convertido en una nada, en un borrón de maniático, en algo que cualquiera es sin más, en algo que se alcanza más fácilmente que la más insignificante habilidad" 2 .

Esta deconstrucción de la cristiandad tiene como fin alcanzar la esencia del cristianismo, su verdadera naturaleza. Antes de la epokbé husserliana, Søren Kierkegaard practica una reducción eidética y trascendental del cristianismo, cuyo fin consiste en trascender las apariencias, poner entre paréntesis las visiones comunes de lo que significa ser cristiano, los tópicos y los prejuicios que enmascaran y ocultan la verdadera esencia del cristianismo, para captar la esencia, la verdadera naturaleza del mismo, lo que es en sí mismo. El filósofo danés relaciona este cristianismo depurado de sus incrustaciones históricas con el orden de la existencia y no de la esencia, con la esfera de la vida subjetiva y no de la dimensión conceptual.

El pensador danés concibe esta tarea como una exigencia, como una forma de sacrificio total y absoluto, que tiene su fuerza motriz en una llamada acaecida en el interior de su espíritu, en una llamada que entiende que no puede rehusar y, a la cual, debe corresponder con fidelidad, entrega total y espíritu de abnegación.

\section{Ser contemporáneo de Cristo}

Ser cristiano significa, a su juicio, hacerse contemporáneo de Cristo y esto sólo puede ser en el tiempo presente (cada tiempo presente, el de cada individuo), reconociendo la distancia insondable entre Dios y el hombre, que conduce a un terrible dolor y a un camino lleno de dificultades, pero que finalmente conlleva a la verdad, a lo que Søren Kierkegaard denomina la verdad para mí.

En la cristiandad, el domingo se dedica a Dios (el oficio religioso) y el resto de la semana, a las tareas cotidianas. El cristiano, en la cristiandad moderna, tal y como lo concibe Søren Kierkegaard, cree que puede armonizar perfectamente la relación con Dios (el domingo) y la relación con lo finito (ir al parque a pasear). La verdadera actitud cristiana, tal como la comprende el escritor danés, consiste en vivir en tensión la relación con el absoluto y la relación con lo relativo.

El cristiano está llamado a morir a lo inmediato. He ahí la razón de su sufrimiento y, además, se trata de un sufrimiento callado y oculto, porque el

${ }^{2}$ Søren Kierkegaard, Ejercitación del cristianismo, Madrid: Trotta, 2009, p. 88. 
hombre religioso no puede expresar exteriormente su interioridad religiosa. Su vida exterior es semejante a la de los demás.

Quien sigue la invitación, desde la interioridad, se hace contemporáneo de Cristo, el Absoluto, se hace 'esencialmente', un cristiano, que reconoce que la vida de Cristo sobre la tierra no es pasado, sino eternidad, mientras que rechaza la pretensión de enseñarlo, en tanto la aceptación implica humildad, temor y temblor.

Ser cristiano consiste en no estar jamás satisfecho con el modo de habitar el mundo, de obrar, de actuar. Es una permanente lucha contra la buena consciencia. El verdadero cristiano nunca se siente del todo cristiano, percibe que siempre está en camino hacia Algo, o mejor dicho, hacia Alguien que le trasciende. 